\title{
PENGARUH KINERJA KEUANGAN TERHADAP KEBIJAKAN DIVIDEN (STUDI PADA INDUSTRI PERBANKAN YANG TERDAFTAR DI BEI)
}

\author{
Rosmita Rasyid ${ }^{1}$ \\ Jurusan Akuntansi, Universitas Tarumanagara, Jakarta \\ rosmitar@fe.untar.ac.id
}

ABSTRAK

\begin{abstract}
Pemegang saham berkepentingan untuk memperoleh pengembalian investasinya secara berkala dalam bentuk dividen yang dibagikan oleh perusahaan. Agar dapat membagi dividen, perusahaan haruslah memiliki kinerja keuangan yang sehat.Penelitian empiris mengenai pengaruh kinerja keuangan terhadap kebijakan dividen yang selama ini sering dilakukan adalah atas perusahaan manufaktur yang memberikan hasil yang berbeda-beda dan masih sedikit penelitian yang dilakukan pada industri perbankan.Tujuan penelitian ini dilakukan untuk melihat bagaimana pengaruh kinerja keuangan yang tercermin dari rasio-rasio keuangan terhadap kebijakan dividen pada industri perbankan. Kinerja keuangan perbankan ditinjau dari sisi kemampulabaan, permodalan dan likuiditas yang dalam hal ini dicerminkan dari rasio Return on Asset (ROA), Return On Equity (ROE), Net Interest Margin (NIM), Capital Adequacy Ratio (CAR), Non Performing Loan (NPL), dan Loan to Deposit Ratio (LDR) dan kebijakan dividen dicerminkan dari rasio Dividend Payout Ratio (DPR). Penelitian dilakukan pada industri perbankan yang go public di Bursa Efek Indonesia pada periode 2010-2014.Terdapat 29 perusahaan bank yang go public di Bursa Efek Indonesia pada periode 2010-2014. Penelitian ini menggunakan analisis regresi berganda yang diolah dengan EVIEWs. Hasil penelitian menunjukkan variabel $R O A, C A R$ dan $L D R$ berpengaruh negatif signifikan terhadap $D P R$, namun variabel $N I M, R O E$ dan $N P L$ tidak berpengaruh secara signifikan terhadap $D P R$.
\end{abstract}

Keywords: KinerjaKeuangan, Bank, Kebijakan Dividen

\section{PENDAHULUAN}

Setiap perusahaan bisnis menginginkan untuk memiliki kinerja keuangan yang baik agar perusahaan dapat bertumbuh dan berkembang dan dapat memberikan tingkat return yang optimal bagi pihak-pihak yang berkepentingan dengan perusahaan. Pihak tersebut salah satunya adalah pemegang saham pada perusahaan yang berbentuk perseroan terbatas (PT).

Pemegang saham berkepentingan untuk memperoleh pengembalian investasinya secara berkala dalam bentuk dividen yang dibagikan oleh perusahaan. Penerimaan dividen secara kontinyu dapat memberikan imej yang baik dimata pemegang saham bahwa perusahaan dalam kondisi yang baik. Umumnya perusahaan membagikan dividen secara berkala dan menjaga jumlah yang dibagikan tidak berbeda dengan periode sebelumnya, kecuali manejer yakin akan dapat menaikkan jumlah dividen dalam jangka panjang.

Agar dapat membagi dividen perusahaan haruslah memiliki kinerja keuangan yang baik. Kinerja keuangan yang baik membuat perusahaan termasuk perusahaan perbankan, dapat membayarkan dividen dengan tidak mengganggu kebutuhan dana untuk keperluan lainnya seperti investasi, pembayaran hutang dan stock repurchase.

Bank merupakan perantara keuangan yang menerima deposit dan menyalurkannya dalam bentuk kredit. Bank menurut Undang-undang No.10 tahun 1998 berfungsi sebagai perantara keuangan yang menghimpun dana dari masyarakat yang kelebihan dana dan menyalurkan dana kepada pihak yang membutuhkannya. Bank yang telah go public juga harus membayarkan dividen kepada pemegang sahamnya.

Penelitian empiris mengenai pengaruh kinerja keuangan terhadap kebijakan dividen yang selama ini sering dilakukan adalah atas perusahaan manufaktur, dan memberikan hasil yang berbeda-beda. Penelitian pengaruh kinerja keuangan terhadap kebijakan dividen yang dilakukan terhadap perusahaan bank yang telah go public masih sedikit dilakukan dan juga memberikan hasil yang berbeda.

Penelitian mengenai dividen telah dilakukan pada tahun 1961 oleh Miller dan Mondigliani dalam Talla (2003) yang menemukan bahwa apabila tidak ada pajak, biaya transaksi, atau ketidakseimbangan pasar lainnya, maka kebijakan dividen tidak mempengaruhi nilai perusahaan. Sedangkan hasil penelitian Efendri 
(1993) dalam Hatta (2002) menunjukkan bahwa faktor peningkatan dan penurunan laba termasuk faktor yang sangat penting dipertimbangkan manajemen dalam kebijakan pembagian dividen kas. Namun menurut hasil penelitian Karuan, Murni dan Tulung (2017) menemukan bahwa profitabilitas tidak berpengaruh terhadap kebijakan dividen.

Sutoyo, Prasetio dan Kusumaningrum (2011) meneliti faktor-faktor yang mempengaruhi dividend payout ratio pada perusahaan jasa keuangan menemukan likuiditas tidak berpengaruh signifikan terhadap kebijakan dividen. Hal sebaliknya ditemukan oleh Sumantri dan Candraningrat (2014) yang menunjukkan likuiditas berpengaruh signifikan terhadap kebijakan dividen.

Pada penelitian ini bertujuan untuk meneliti kembali pengaruh kinerja keuangan terhadap kebijakan dividen pada industri perbankan yang go public di Bursa Efek Indonesia. Pengukuran kinerja keuangan pada industri perbankan menggunakan variabel rasio Return On Assets (ROA), Return On Equity (ROE), Net Interest Margin (NIM), Capital Adequacy Ratio (CAR), NonPerforming Loan (NPL), Loan to Deposit Ratio (LDR). Kebijakan dividen diukur dari Dividend Payout Ratio (DPR). Adapun rumusan permasalahan adalah apakah: (1) Return On Assets (ROA) berpengaruh pada Dividend Payout Ratio (DPR), (2) Return On Equity (ROE) berpengaruh pada Dividend Payout Ratio (DPR), (3) Net Interest Margin (NIM) berpengaruh pada Dividend Payout Ratio (DPR), (4) Capital Adequacy Ratio (CAR) berpengaruh pada Dividend Payout Ratio (DPR), (5) Non Performing Loan (NPL) berpengaruh pada Dividend Payout Ratio (DPR), (6) Loan to Deposit Ratio $(L D R)$ berpengaruh pada Dividend Payout Ratio (DPR), pada industri perbankan yang go public di Bursa Efek Indonesia.

Urgensi penelitian ini adalah menambah wawasan bagi investor perusahaan dalam menganalisis dan memutuskan untuk melakukan pembelian saham bank. Bagi manajemen bank diharapkan hasil penelitian ini memudahkan manajemen dalam melakukan pengambilan keputusan mengenai pembayaran dividen ataupun untuk melakukan reinvestasi laba yang diperoleh. Sedangkan bagi akademisi diharapkan dapat menambah pengetahuan dan pengembangan keilmuan.

\section{METODE PENELITIAN}

Penelitian ini merupakan penelitian deskriptif yang menjelaskan pengaruh kinerja keuangan bank terhadap kebijakan dividen bank tersebut. Penelitian dilakukan atas data sekunder berupa laporan keuangan bank yang go public yang melakukan pembayaran dividen pada periode tahun 2010 sampai dengan 2014 .

Jenis data yang digunakan adalah data panel yaitu kombinasi crossection dan time series. Crosssection terdiri dari bank yang go public di Bursa Efek Indonesia, sedangkan time series yaitu periode 2010 sampai 2014 atau selama 5 tahun. Penelitian ini menggunakan analisis regresi berganda yang diolah dengan EVIEWs.

Model penelitian ini menggunakan analisis regresi berganda dengan Kinerja Keuangan sebagai variabel independen, sedangkan Kebijakan Dividen merupakan variabel dependen.Variabel kinerja keuangan bank merupakan variabel independen yang terdiri dari Return On Asset (ROA), Return On Equity (ROE), Net Interest Margin (NIM), Capital Adequacy Ratio (CAR), Non Performing Loan (NPL), Loan to Deposit Ratio (LDR), dan variabel dependennya kebijakan dividen yang diukur dari Dividend Payout Ratio(DPR).

Model penelitian ini adalah sebagai berikut:

$D P R_{i t}=a_{i t}+b R O A_{i t}+c R O E_{i t}+d N I M_{i t}+e C A R_{i t}+f N P L_{i t}+g L D R_{i t}+e_{i t}$

Divident Payout Ratio (DPR) merupakan variabel dependen, sedangkan kinerja keuangan yang diproxikan dengan Return On Asset (ROA), Return On Equity (ROE),Net Interest Margin (NIM), Capital Adequacy Ratio (CAR), Non Performing Loan (NPL), Loan to Deposit Ratio (LDR). 


\section{HASIL DAN PEMBAHASAN}

Subyek penelitian ini adalah industri perbankan yang go public di Bursa Efek Indonesia pada periode 2010-2014 adalah sebagai berikut: 1. Bank Rakyat Indonesia Agro Niaga Tbk (Agro), 2. Bank MNC Internasional Tbk (Babp), 3. Bank Capital Indonesia, Tbk (Baca), 4. Bank Central Asia Tbk (Bbca), 5. Bank Bukopin Tbk, (Bbkp), 6. Bank Negara Indonesia (Persero) Tbk (Bbni), 7.Bank Nusantara Parahyangan Tbk (bbnp), 8. Bank Rakyat Indonesia (Persero) (Bbri), 9. Bank Tabungan Negara (Persero) Tbk (Bbtn), 10. Bank J Trust Indonesia Tbk (Bcic), 11. Bank Danamon Indonesia (Bdmn), 12. Bank Pembangunan Daerah Banten Tbk (Beks), 13. Bank Jabar Banten Tbk (Bjbr), 14. Bank QNB Indonesia Tbk (Bksw), 15. Bank Mandiri (Persero) Tbk (Bmri), 16. Bank CIMB Niaga Tbk (Bnga), 17. Bank Maybank Indonesia Tbk (Bnii), 18.Bank Permata Tbk (Bnli), 19. Bank Sinar Mas (Bsim), 20. Bank of India Indonesia Tbk (Bswd), 21. Bank Tabungan Pensiun Nasional (Btpn), 22. Bank Victoria Tbk (Bvic), 23. Bank Artha Graha International (Inpc), 24. Bank Mayapada International Tbk (Maya), 25. Bank China Construction Ind Tbk (Mcor), 26. Bank Mega Tbk (Mega), 27. Bank OCBC NISP Tbk (Nisp), 28.Bank Pan Indonesia Tbk (Pnbn), 29. Bank Woori Saudara Indonesia 1906 Tbk (Sdra).

Tabel 1 pada halaman 4 memperlihatkan statistik deskriptif dari variabel-variabel yang digunakan yakni variabel independen berupa rasio Return On Asset (ROA), Return On Equity (ROE), Net Interest Margin (NIM),Capital Adequacy Ratio (CAR), Non Performing Loan (NPL), Loan to Deposit Ratio (LDR). Variabel dependennya adalah Dividend Payout Ratio (DPR).

Dari hasil deskriptif statistik pada tabel 1 pada halaman 4, terlihat bahwa nilai maksimum CAR adalah 46,4900 dan nilai minimum 9,4100, nilai rata-rata 16,57684 dengan standar deviasi 5,727193. Nilai maksimum DER adalah 66.6700 dan nilai minimum 0,0000 nilai rata-rata 11,91317 dengan standar deviasi 17,63872. Nilai maksimum $L D R$ adalah 113,3000 dan nilai minimum 0,8496 , nilai rata-rata 79,72842 dengan standar deviasi 16,30325.

Tabel 1: Statistik Deskriptif Data

\begin{tabular}{|l|l|r|r|}
\hline Variabel & Mean (SD) & Minimum & Maksimum \\
\hline CAR & $\begin{array}{l}16,57684 \\
(5,727193)\end{array}$ & 9,4100 & 46,4900 \\
\hline DPR & $\begin{array}{l}11,91317 \\
(17,63872)\end{array}$ & 0,0000 & 66,6700 \\
\hline LDR & $\begin{array}{l}79,72842 \\
(16,30325)\end{array}$ & 0,8496 & 113,3000 \\
\hline NIM & $\begin{array}{l}5,752933 \\
(2,532122)\end{array}$ & 0,2400 & 16,6400 \\
\hline NPL & $\begin{array}{l}2,916785 \\
(4,790963)\end{array}$ & 0,0000 & 51,0000 \\
\hline ROA & $\begin{array}{l}1,800555 \\
(2,064065)\end{array}$ & $-13,0000$ & 5,1502 \\
\hline ROE & $\begin{array}{l}13,53546 \\
(21,45631)\end{array}$ & 142,4800 & 68,0900 \\
\hline
\end{tabular}

Dari Tabel 1 terlihat bahwa nilai maksimum NIM adalah 16,6400 dan nilai minimum 0,2400, nilai rata-rata 5,752933 dengan standar deviasi 2,532122. Nilai maksimum $N P L$ adalah 51,0000 dan nilai minimum 0,0000 , nilai rata-rata 2,916785 dengan standar deviasi 4,790963. 
Nilai maksimum $R O A$ adalah 5,1502 dan nilai minimum -13,0000, nilai rata-rata 1,80055 dengan standar deviasi 2,064065. Nilai maksimum $R O E$ adalah 68,09 dan nilai minimum 142,4800 , nilai rata-rata 13,53546 dengan standar deviasi 21,45631.

Tabel 2. Korelasi Antar Variabel Independen

\begin{tabular}{|l|r|r|r|r|r|r|}
\hline & \multicolumn{1}{|l|}{ CAR } & \multicolumn{1}{l|}{ LDR } & \multicolumn{1}{l|}{ NIM } & \multicolumn{1}{l|}{ NPL } & \multicolumn{1}{l|}{$R O A$} & \multicolumn{1}{c|}{$R O E$} \\
\hline CAR & 1,000 & $-0,014$ & 0,100 & 0,148 & $-0,058$ & $-0,093$ \\
\hline LDR & $-0,014$ & 1,000 & 0,154 & $-0,108$ & 0,110 & $-0,151$ \\
\hline NIM & 0,100 & 0,154 & 1,000 & $-0,123$ & 0,360 & 0,210 \\
\hline NPL & 0,148 & $-0,108$ & $-0,123$ & 1,000 & $-0,680$ & $-0,473$ \\
\hline$R O A$ & $-0,058$ & 0,110 & 0,360 & $-0,680$ & 1,000 & 0,816 \\
\hline$R O E$ & $-0,093$ & $-0,151$ & 0,210 & $-0,473$ & 0,816 & 1,000 \\
\hline
\end{tabular}

Dari tabel 2 terlihat bahwa variabel $R O A$ dan $R O E$ memiliki korelasi yang cukup tinggi. Akan tetapi, kedua variabel tersebut tetap digunakan dalam model regresi karena merupakan variable of interest bagi peneliti. Nilai Durbin Watson statistic sebesar 2.098050 atau masih berada pada interval nilai 1,5-2,5. Berdasarkan Field (2009), nilai Durbin Watson statistik dengan rentang nilai 1,5-2,5 tidak menunjukkan gejala terjadinya autokorelasi.

Hasil uji chow pada tabel 3 di halaman 5, memiliki probabilitas dibawah 0,05 sehingga H0 ditolak, model panel disarankan menggunakan estimasi fixed effect. Oleh sebab itu, penelitian ini menggunakan estimasi fixed effect.

Tabel 3. Hasil Uji Redundant Fixed Effect dan Uji Hausman

\begin{tabular}{|l|r|l|l|}
\hline & Cross Section-F & $\begin{array}{l}\text { Cross Section } \\
\text { Random }\end{array}$ & Prob \\
\hline $\begin{array}{l}\text { Redundant Fixed Effect } \\
\text { Test }\end{array}$ & 8,012 & - & \\
0,000 \\
\hline
\end{tabular}

Tabel 4. Hasil Regresi

\begin{tabular}{|l|l|}
\hline & $D P R$ \\
\hline \multirow{2}{*}{$C$} & $\begin{array}{l}17.30000 \\
(2.528419)^{* * *}\end{array}$ \\
\hline \multirow{2}{*}{$C A R$} & $\begin{array}{l}-0.236060 \\
(0.115799)^{* *}\end{array}$ \\
\hline \multirow{2}{*}{$L D R$} & $\begin{array}{l}-0.053895 \\
(0.024304)^{* *}\end{array}$ \\
\hline \multirow{2}{*}{$N I M$} & $\begin{array}{l}0.773374 \\
(0.486266)\end{array}$ \\
\hline \multirow{2}{*}{$N P L$} & $\begin{array}{l}0.022121 \\
(0.100865)\end{array}$ \\
\hline \multirow{2}{*}{$R O A$} & $\begin{array}{l}-1.314575 \\
(0.504414)^{* *}\end{array}$ \\
\hline
\end{tabular}




\begin{tabular}{|l|r|} 
ROE & $\begin{array}{l}\text { 0.049984 } \\
(0.045535)\end{array}$ \\
\hline $\begin{array}{l}\text { Year Random } \\
\text { Effect }\end{array}$ & \multicolumn{1}{|l|}{150} \\
\hline Obs & 0.623553 \\
\hline Adj. R-squared & 0.000000 \\
\hline Prob-F & \\
\hline
\end{tabular}

**: Hasil Uji t signifikan pada $\alpha=0.05$

Hasil pengujian regresi pada Tabel 4 di atas dengan menggunakan tingkat keyakinan 95\%, Berdasarkan hasil regresi, variabel ROA signifikan negatif mempengaruhi DPR. Hal ini terlihat dari konstanta ROA adalah - 1,315 ketika ada peningkatan nilai ROA sebesar 1 satuan, DPR akan menurun sebesar 1,315 satuan secara statistik. Peningkatan ROA kemungkinan disebabkan oleh meningkatnya kenaikan laba perusahaan lebih besar dari kenaikan aset bank. Peningkatan laba ini kemungkinan lebih banyak digunakan untuk pengembangan bank atau ditahan oleh bank untuk keperluan bank tersebut. Hal ini berpengaruh terhadap jumlah dividen yang dibayarkan kepada pemegang saham yang berkemungkinan menjadi menurun atau berkurang.

Hasil regresi di atas juga menunjukkan bahwa variabel NIM, dan variabel ROE tidak berpengaruh secara signifikan terhadap DPR. Variabel NIM dan ROE merupakan ukuran profitabilitas dalam pengukuran kinerja, termasuk juga ROA. Namun hasil regresi ROE dan NIM tidak konsisten dengan ROA

Variabel CAR signifikan mempengaruhi DPR secara negatif. Hal ini ditunjukkan oleh nilai konstanta CAR adalah -0,236. Artinya bila ada kenaikan nilai CAR sebesar 1 satuan akan menurunkan nilai DPR sebesar 0,236 satuan. Peningkatan CAR berakibat pada penurunan DPR kemungkinan disebabkan pihak bank menahan modalnya untuk pengembangan usaha sehingga menurunkan jumlah yang dibayarkan sebagai dividen kepada pemegang saham bank tersebut.

Variabel LDR signifikan mempengaruhi nilai DPR secara negatif. Hal ini ditunjukkan LDR adalah oleh nilai konstanta -0,054. Artinya bila ada kenaikan nilai LDR sebesar 1 satuan akan menurunkan nilai DPR sebesar 0,054 satuan. Peningkatan LDR berakibat pada penurunan DPR kemungkinan disebabkan pihak bank menambah likuiditasnya untuk pengembangan usaha sehingga menurunkan jumlah yang dibayarkan sebagai dividen kepada pemegang saham bank tersebut.

LDR merupakan ukuran likuiditas dan NPL juga termasuk dalam ukuran likuiditas, namun variabel NPL tidak berpengaruh secara signifikan terhadap DPR. Hal ini menunjukkan hasil yang tidak konsisten.

\section{Kesimpulan}

Berdasarkan hasil regresi, variabel ROA signifikan negatif mempengaruhi DPR. Peningkatan ROA kemungkinan disebabkan oleh meningkatnya kenaikan laba perusahaan lebih besar dari kenaikan aset bank. Peningkatan laba ini kemungkinan lebih banyak digunakan untuk pengembangan bank atau ditahan oleh bank untuk keperluan bank tersebut. Hal ini berpengaruh terhadap jumlah dividen yang dibayarkan kepada pemegang saham yang berkemungkinan menjadi menurun atau berkurang.

ROA merupakan ukuran profitabilitas dalam pengukuran kinerja yang memberikan pengaruh negatif terhadap DPR. Meskipun demikian, NIM dan ROE yang juga sebagai ukuran profitabilitas, namun tidak mempengaruhi DPR, sehingga dapat disimpulkan ukuran profitabilitas memberikan pengaruh yang berbedabeda terhadap DPR. 
Hasil regresi, variabel LDR signifikan negatif mempengaruhi DPR. Peningkatan LDR berakibat pada penurunan DPR kemungkinan disebabkan pihak bank menambah likuiditasnya untuk pengembangan usaha sehingga menurunkan jumlah yang dibayarkan sebagai dividen kepada pemegang saham bank tersebut.

LDR merupakan ukuran likuiditas yang memberi pengaruh negatif terhadap DPR. NPL meskipun tergolong variabel likuiditas, namun tidak mempengaruhi DPR, sehingga dapat disimpulkan bahwa ukuran likuiditas memberikan pengaruh yang berbeda-beda terhadap DPR.

Berdasarkan hasil regresi, variabel CAR signifikan negatif mempengaruhi DPR. Peningkatan CAR berakibat pada penurunan DPR kemungkinan disebabkan pihak bank menahan modalnya untuk pengembangan usaha sehingga menurunkan jumlah yang dibayarkan sebagai dividen kepada pemegang saham bank tersebut.

\section{Referensi}

Al-Deehanii, Talla M (2003) Determinants of Dividen Policy: The Case of Kuwait, Journal of Economic \& Administrative Sciences Vol. 19, No. 2, December 2003 (59-76)

Gozali, Imam (2013) AplikasiAnalisis Multivariate dengan Program IBM SPSS 21, Semarang: UniversitasDiponegoro

Hatta, AtikaJauhari (2002). Faktor-faktor yang MempengaruhiKebijakan Dividen: InvestigasiPengaruhTeoriStakeholder. JurnalAkuntansi\&Auditing Indonesia. Vol.6 No.2 (Des). 1-22

Husnan, Suad (2010). Manajemen Keuangan Teori dan Penerapan, Edisi keempat, Yogyakarta: BPFE

Ikatan Akuntan Indonesia, (2012), Standar Akuntansi Keuangan, Jakarta, Salemba Empat.

Karuan Prisilia, Sri Murni dan Joy Tulung (2017), Pengaruh Kinerja Keuangan Terhadap Kebijakan Dividen Pada Bank BUMN Yang Go Public di Bursa Efek Indonesia Tahun 2011-2015, Jurnal EMBA Vol.5 No.2 Juni 2017, Hal. 935 - 944

Keown, Arthur J., John D. Martin, J. William Petty, David F. Scott, JR, (2005). Financial Management. Tenth edition, New Jersey: Prentice-Hall, Inc

Kimmel, Paul D., Jerry J. Weygandt, DonaldE.Kieso. (2013), Intermediate Accounting, IFRS $2^{\text {nd }}$ Edition, New Jersey, John Wiley \& Sons, Inc.

Mishkin, Frederic S., Stanley G. Eakins. (2009), Financial Markets and Institutions, Sixth edition, Boston, Pearson International Education

Sutoyo, Januar Eko Presetio dan Dian Kusumaningrum (2011), Faktor-Faktor Yang Mempengaruhi Dividend Payout Ratio Pada Perusahaan Jasa Keuangan, Jurnal Keuangan dan Perbankan, Volume 15.No.1, Januari 2011

Talla, M Al Deehani, Determinants of Dividend Policy: The Case of Kuwait, Journal of Economic \& Administrative Sciences, Vol.19, No.2, December 2003

Weygandt, Jerry J, Paul D. Kimmel and Donald E. Kieso (2013), Financial Accounting IFRS $2^{\text {nd }}$ Edition, United States, John Wiley \& Sons.

Yiadom, Edward Marfo and Samuel KwakuAgyei, Determinants of Dividend Policy of Banks in Ghana, International Research Journal of Finance and Economics, ISSN 1450-2887 Issue 61 (2011), Euro Journals Publishing, Inc.2011, http://www.eurojournals.com/finance.htm 